\title{
ARTIGO
}

\section{LIMITES DA EAD PARA A MATERIALIZAÇÃO DO DIREITO À EDUCAÇÃO: UM ESTUDO SOBRE A EVASÃO}

\begin{abstract}
Limits of distance education in the materialization of the right for education: a study about
\end{abstract} evasion

Limites de la EAD para la materialización del derecho a la educación: un estudio sobre la evasión

Maria Marley Tedesco Radin Universidade Católica de Pelotas - Brasil

Stivie Sena Leston

Universidade Católica de Pelotas - Brasil

Myriam Siqueira da Cunha

Universidade Católica de Pelotas - Brasil

\begin{abstract}
Resumo
Este artigo resulta de uma pesquisa que investigou fatores que influenciam a evasão de alunos na educação a distância. A unidade de análise foi o Curso de Licenciatura em Matemática a Distância, ofertado pela UFPel, vinculado à Universidade Aberta do Brasil. Foi realizado um estudo de caso, de abordagem qualitativa. Para coleta de dados, realizou-se entrevistas semiestruturadas com coordenadores, professores, tutores e alunos evadidos, além de análise documental. Os achados foram analisados em três momentos interligados, que envolveram: 1) desmontagem dos textos em unidades de significado; 2) estabelecimento de relações entre essas unidades, para promover a sua categorização; e 3) emergência de um entendimento renovado do todo. Os resultados indicam que a evasão está ligada ao desconhecimento sobre a Educação a Distância, a não adequação à sua metodologia de ensino e a não consideração da importância da dedicação aos estudos. Outros fatores que levaram à evasão foram: demora de feedback por parte dos tutores; frustração das expectativas com relação ao curso; percepção de ensino com baixa qualidade; e demandas simultâneas ao curso, relativas ao trabalho e à família.
\end{abstract}

Palavras-chave: Educação a distância. Educação superior. Evasão.

\section{Abstract}

This article is the result of a study that investigated factors associated with evasion in students of distance education. The unit of analysis was the undergraduate Distance Course of Math, 
offered by the UFPel, bound to the Open University of Brazil program. A case study was done, of qualitative approach. For data collection, semi-structured interviews were conducted with coordinators, teachers, tutors and evading students, in addition to document analysis. The findings were analysed in three interconnected moments, involving: 1) deconstruction of the texts into units of meaning; 2) establishment of relationships between these units, in order to promote categorization; and 3) emergence of a renewed understanding of the bigger picture. The results indicate that evasion is connected to lack of knowledge about Distance Education, non-adequacy of the teaching method and the non-consideration of how important study dedication is. Other factors that led to evasion were: delay in feedback by the tutors; frustrated expectations in relation to the course; low quality teaching; campus infrastructure; simultaneous demands during the course, related to work and family.

Keywords: Distance Education. Higher Education. Evasion.

\section{Resumen}

Este artigo resulta de una pesquisa que investigó factores que influencian en la evasión de alumnos en la educación a distancia. La unidad de análisis fue el Curso de Grado en Matemática a Distancia, ofertado por la UFPEL, vinculado a la Universidad Abierta de Brasil. Fue realizado un estudio de caso, de enfoque cualitativo. Para la coleta de los datos, se realizaron entrevistas semiestructuradas con coordinadores, profesores, tutores y alumnos evadidos, además de análisis documental. Los resultados fueron analizados en tres momentos entrelazados, que implicaron: 1) desmantelamiento de los textos en unidades de significado; 2) estabelecimiento de relaciones entre esas unidades, para promover su categorización; y 3) emergencia de un entendimiento renovado del todo. Las conclusiones indican que la evasión está entrelazada al desconocimiento sobre la Educación a Distancia, a la inadecuación de su metodología de enseño, y a la desconsideración de la importancia de la dedicación a los estudios. Otros factores que llevaron a la evasión fueron: enseño de baja cualidad; infraestructura del Polo; y las demandas simultaneas al curso, relativas al trabajo y la familia.

Palabras clave: Educación a Distancia. Educación Superior. Evasión.

\section{Introdução}

A democratização do acesso à educação superior é questão complexa e relevante para a sociedade brasileira, principalmente no cenário contemporâneo, de globalização, revolução tecnológica e mudanças nas relações de trabalho. Além disso, o ensino superior não tem sido pleno no que se refere ao alcance de todos e em relação à conclusão dos diferentes níveis de escolaridade (JOHANN, 2012).

Nesse contexto, a Educação a Distância (EaD) aparece como possibilidade e alternativa para atender à missão educacional de maneira mais ampliada, tendo papel central para a democratização do acesso à informação, à cultura e à educação superior. A EaD parece ser uma modalidade adequada para promoção da inclusão social, permitindo integrar grande 
número de pessoas que vivem distantes de centros educacionais ou impossibilitadas de frequentar cursos presenciais.

Contudo, de acordo com as instituições que ofertam essa modalidade, a evasão dos alunos tem sido um dos seus maiores obstáculos. Sobre isso, o Relatório Analítico da Aprendizagem a Distância no Brasil informa que, em 2013, o índice de evasão, segundo o Censo EaD.BR 2013, aumentou em todos os cursos e disciplinas. Entre as principais causas apontadas estão: falta de tempo dos alunos para estudar e participar dos cursos, acúmulo de atividades e falta de adaptação à metodologia da $\mathrm{EaD}$.

No Curso de Licenciatura em Matemática a Distância (CLMD) da Universidade Federal de Pelotas (UFPel), foram oferecidas 1100 vagas em 2011/1, matriculados 960 alunos, formados 259 alunos, distribuídos em 22 polos da região sul. Desse total de 960 matriculados, 651 alunos evadiram, o que representa 67,81\% dos matriculados (ABED, 2013).

No Polo de Apoio ao Ensino a Distância pesquisado, foram ofertadas 50 vagas, matriculados 50, formados 23, e 24 alunos evadiram. O índice de evasão foi de $48 \%$, sendo superior à média geral de 16,94\% dos cursos autorizados pelo Ministério da Educação (MEC) (ABED, 2013).

Considerando a importância que o tema assume no cenário da $\mathrm{EaD}$, a pesquisa feita buscou investigar fatores que influenciaram na evasão de alunos no curso em análise, a partir da perspectiva de coordenadores, tutores, professores e alunos evadidos.

\section{Políticas de educação, Ead e evasão}

As políticas educacionais estão alicerçadas em conceitos, procedimentos e projetos daqueles que estão no poder em cada período histórico. Toda vez que é empossado um novo Secretário ou Ministro de Educação, suas ideias e intenções tornam-se o viés da política educacional; dessa forma, pouco se trabalha com política educacional de longo prazo (SOUZA, 1997).

A partir dessa visão particular, individual e quase pessoal, uma diversidade de políticas é praticada, muitas vezes sem contribuir de forma efetiva para as mudanças necessárias.

Nesse cenário, o século XX foi palco de várias reformas educacionais no Brasil e, apesar de serem travadas muitas discussões, poucas mudanças se refletiram em sala de aula. 
Conforme Souza (1997), nem a Lei de Diretrizes e Bases (LDB), nem a Constituição mostraram caminhos seguros para aplicação de uma política educacional adequada.

A vista disso, foi elaborado em 2001 o Plano Nacional de Educação (PNE) para o período de 2001 a 2010, com um conjunto de metas e diretrizes que visavam balizar e orientar a educação no país. O PNE foi construído sobre três eixos: a educação como direito da pessoa, a educação como fator de desenvolvimento econômico e social e, por fim, a educação como meio de combate à pobreza. Atualmente, ele está em nova fase, estabelecida desde 2014 até 2024, construído nas mesmas bases do anterior (MEC, 2013)

Desse modo, nos últimos anos, a educação brasileira passou por reformas, entre elas, a universalização dos primeiros anos do ensino fundamental, a implantação da Rede Federal de Educação Tecnológica, oferecendo ensino médio para jovens, a expansão da rede municipal para a educação infantil, bem como o estímulo de ações voltadas ao atendimento especial e à educação para jovens e adultos (BRASIL, 2014).

A importância do PNE se expressa no seu conteúdo e nas suas diretrizes, a saber:

[...] erradicação do analfabetismo; universalização do atendimento escolar; superação das desigualdades educacionais, com ênfase na promoção da cidadania e na erradicação de todas as formas de discriminação; melhoria da qualidade da educação; formação para o trabalho e para a cidadania, com ênfase nos valores morais e éticos em que se fundamenta a sociedade; promoção do princípio da gestão democrática da educação pública; promoção humanística, científica, cultural e tecnológica do País; estabelecimento de meta de aplicação de recursos públicos em educação como proporção do Produto Interno Bruto - PIB, que assegure atendimento às necessidades de expansão, com padrão de qualidade e equidade; valorização dos (as) profissionais da educação; promoção dos princípios do respeito aos direitos humanos, à diversidade e à sustentabilidade socioambiental (BRASIL, 2014).

Tanto as metas quanto as estratégias apresentam iniciativas para todos os níveis, modalidades e etapas educacionais. Além disso, há estratégias específicas para a inclusão de minorias, como alunos com deficiência, indígenas, quilombolas, estudantes do campo e alunos em regime de liberdade assistida (MEC, 2013).

O referido plano dá destaque à elaboração de currículos básicos e avançados em todos os níveis de ensino e à diversificação de conteúdos curriculares. Prevê a correção de fluxo e o combate à defasagem idade-série. São instituídas metas para o aumento da taxa de alfabetização e da escolaridade média da população (MEC, 2013).

Apesar dos avanços, muitas questões permanecem em discussão e dizem respeito à tensão entre centralização x descentralização, qualidade x quantidade e a relação entre o 
público e o privado na educação. Como já mencionado, muitos são os desafios educacionais e, nesse contexto, a Educação a Distância pode ser um meio da superação desses desafios ou apenas mais uma de suas expressões.

Nos discursos oficiais, a EaD passou de uma ação eventual para uma articulada e planejada política nacional de formação inicial superior para docentes, tornando-se uma alternativa para qualificação da formação de professores e, consequentemente, para formação básica (CASTRO, 2004).

Assim, as políticas de governo passam a destacar a Educação a Distância como meio de acesso ao conhecimento e de democratização do ensino com baixos custos (CASTRO, 2004).

No que concerne à sua trajetória em território nacional, a $\mathrm{EaD}$ foi inserida na legislação educacional em 1996, com a nova Lei de Diretrizes e Bases da Educação Nacional (LDB), $n^{\circ}$ 9.394/1996, que reconhece essa modalidade de educação no seu artigo 80 (BRASIL, 1996).

Em fevereiro de 1998, as iniciativas de Educação a Distância foram normatizadas pelo artigo $2^{\circ}$ do Decreto $n^{\circ} 2494 / 98$, que diz:

[...] os cursos a distância que conferem certificado ou diploma de conclusão do ensino fundamental para jovens e adultos, do ensino médio, da educação profissional e de graduação serão oferecidos por instituições públicas ou privadas especificamente credenciadas para esse fim [...]. (BRASIL, 1998).

Nesse período, foi instituída, pelo Ministério da Educação (MEC), a Universidade Aberta do Brasil (UAB), como um sistema formado por universidades públicas, que oferece cursos superiores na modalidade a distância a fim de democratizar, expandir e interiorizar a oferta de ensino público e gratuito no Brasil (MILL, 2012).

Com o surgimento do Sistema UAB, o Brasil iniciou uma nova fase da EaD. Nesse contexto, um dos temas de maior preocupação dos gestores da UAB, nas Instituições de Ensino Superior, foram os altos índices de evasão (MILL, 2012).

Para Mill (2012), manter os alunos nos cursos é um dos principais desafios dos gestores da UAB. Por conseguinte, isso tem incentivado a pesquisa sobre os motivos dessa evasão e a busca de novas estratégias para solução dessa dificuldade (MILL, 2012).

Destaca-se que a capacidade de resposta da Ead aos desafios educacionais brasileiros tem sido enfraquecida pelos números da evasão. No setor público, a atenção com a evasão está associada ao que o Estado investe na formação dos alunos, tendo em vista que o abandono de uma vaga gera perda significativa de investimento (SILVA FILHO et al., 2007). 
Castro (2012) adverte que a evasão traz consequências negativas às instituições e aos próprios alunos, podendo ocasionar perda financeira e de tempo. Nessa direção, autores ressaltam que o custo social advindo da evasão é muito elevado, considerando que:

[...] no setor público, são recursos públicos investidos sem o devido retorno. No setor privado, é uma importante perda de receitas. Em ambos os casos, a evasão é uma fonte de ociosidade de professores, funcionários, equipamentos e espaço físico. (SILVA FILHO et al., 2007, p. 642).

De acordo com o Censo Ead de 2013, o índice de evasão na EaD é elevado, chegando, em alguns casos, próximo de 65\% (ABED, 2013). Conforme Longo (2009), a evasão é uma questão complexa, resultante de diferentes elementos, tais como: falta de tempo; estranhamento pela mudança de modalidade do presencial para a distância; questões profissionais; insatisfação com o conteúdo; falta de prática no uso das ferramentas; problemas pessoais; opção inapropriada do curso; insatisfação com a tutoria e/ou ausência de tutoria; falta de suporte e problemas técnicos.

Colaborando com esse pensamento, Coelho (2002, s.p.) também cita possíveis indicadores das causas e situações mais frequentes em que ocorrem a evasão:

- A falta da tradicional relação face-a-face entre professor e alunos, pois neste tipo de relacionamento julga-se haver maior interação e respostas afetivas entre os envolvidos no processo educacional;

- Insuficiente domínio técnico do uso do computador, principalmente da Internet, ou seja, a inabilidade em lidar com as novas tecnologias cria dificuldades em acompanhar as atividades propostas pelos cursos a distância como: receber e enviar e-mail, participar de chats, de grupos de discussão e fazer links sugeridos;

- Ausência de reciprocidade da comunicação, ou seja, dificuldades em expor ideias numa comunicação escrita a distância, inviabilizando a interatividade; - A falta de um agrupamento de pessoas numa instituição física, construída socialmente e destinada muitas vezes, à transmissão de saberes, assim como ocorre no ensino presencial tradicional, faz com que o aluno de EAD não se sinta incluído num sistema educacional.

Silveira (2012) investigou os índices e os motivos da evasão na Educação a Distância no Polo UAB de Franca. Foram oferecidas 953 vagas, concentradas em 15 cursos de graduação, especialização e aperfeiçoamento. Desse total, 240 alunos concluíram, 48 desistiram, 137 abandonaram o curso e 534 ainda estavam ativos.

As categorias mais incidentes para análise das causas da evasão foram: limite pessoal, como dificuldade de expor as ideias em uma comunicação escrita a distância, falta de suporte à aprendizagem, fatores do contexto familiar (como o ambiente de estudo), situação financeira, dedicação insuficiente aos estudos, falta de habilidade para conciliar as atividades 
concorrentes com as tarefas exigidas pelo curso, falta de experiência como aluno em cursos a distância, dificuldade para redigir textos e mensagens, e problemas de saúde.

Apesar da importância dessa problemática, ressalta-se que poucas instituições apresentam programas institucionais de enfrentamento à evasão, com planejamento de ações, acompanhamento de resultados e coleta de experiências realizadas com sucesso (SILVA FILHO et al., 2007).

Por fim, salienta-se que dada à sua complexidade, a evasão vem sendo considerada a partir de três perspectivas:

evasão de curso: quando o estudante desliga-se do curso superior em situações diversas tais como: abandono (deixa de matricular-se), desistência (oficial), transferência ou reopção (mudança de curso), exclusão por norma institucional;

evasão da instituição: quando o estudante desliga-se da instituição na qual está matriculado;

evasão do sistema: quando o estudante abandona de forma definitiva ou temporária o ensino superior. (MEC, 1997, p.20).

Neste estudo, o foco esteve voltado para a evasão de curso por iniciativa do aluno, sendo entendida como " $[. .$.$] o ato da desistência, incluindo os que nunca se apresentaram ou$ se manifestaram de alguma forma para os colegas e mediadores do curso, em qualquer momento"' (FAVERO, 2006, p. 50).

\section{Procedimentos metodológicos}

Optou-se pela abordagem qualitativa, pois trabalha com significados, motivos, aspirações, crenças, valores e atitudes, o que corresponde a um espaço mais profundo das relações, dos processos e dos fenômenos que não podem ser reduzidos à operacionalização de variáveis (MINAYO, 2010).

A unidade de análise foi o Curso de Licenciatura em Matemática a Distância da UFPel, no Polo a distância, aqui denominado PAED. A pesquisa utilizou como fontes de evidências para compreender o fenômeno da evasão: sinopses estatísticas e entrevistas.

Nesse cenário, decidiu-se utilizar entrevistas semiestruturadas, tendo em vista que esse tipo de entrevista tem sua condução norteada por uma estrutura flexível, que consiste em questões abertas que definem, inicialmente, o que se quer explorar (SEIDMAN, 1998). Os roteiros de entrevista foram adaptados de Almeida (2007; 2013). Por sua vez, as estatísticas foram buscados nos sites da Associação Brasileira de Educação a Distância (ABED) e do MEC. 
Participaram do estudo o coordenador do curso; o coordenador do polo; o coordenador de tutoria; o coordenador de estágios; seis docentes, de um total de 31; um tutor presencial, de um total de 26; um tutor a distância, de um total de 37; e oito alunos, de um total de 24 evadidos. Os docentes, tutores e alunos evadidos, foram selecionados por sorteio, dentro do grupo ao qual pertenciam. Neste artigo, para garantir o sigilo dos participantes, todos serão tratados por nomes fictícios.

Para análise e interpretação dos dados, foi realizada uma primeira apreciação de documentos pré-existentes e do material de produzido a partir das entrevistas e de registros, convertidos em texto. Tais registros foram reunidos e analisados desde o início da coleta de dados, pelo processo de leitura de todo o material recolhido.

Após essa etapa inicial, o processo analítico passou por três momentos interligados, que envolveram: 1) desmontagem dos textos em unidades de significado; 2) estabelecimento de relações entre essas unidades, para promover a categorização; e 3) emergência de um entendimento renovado do todo, isto é, produção de um novo texto representativo das compreensões do pesquisador acerca do objeto de estudo (MORAES; GALIAZZI, 2007).

Os resultados foram apresentados, discutidos e comparados a outros alcançados em pesquisas anteriores, assim como a posicionamentos de autores de referência na área. Como suporte informacional, foi utilizado o software de apoio à análise de dados qualitativos, NVIVO10.

\section{Resultados e discussão}

O processo de análise dos dados culminou nas seguintes categorias: "não era o curso desejado"; "dificuldade de conciliar atividades relativas à família e ao trabalho com o curso"; "dificuldades acadêmicas"; "falta de suporte e demora no esclarecimento de dúvidas"; "noção de que o ensino EaD não requer dedicação"; "percepção de ensino com baixa qualidade" e "ausência de práticas preventivas à evasão".

\section{Não era o curso desejado}

Sabe-se que o processo de escolha de um curso superior carrega consigo inúmeras expectativas por parte dos estudantes. Entre as principais aspirações dos ingressantes, destacam-se a possibilidade de ascensão social e melhoria das condições financeiras. Nesse cenário, Violin (2012) aponta que parcela significativa dos alunos prioriza o ingresso em 
universidades públicas, em um curso com mercado de trabalho promissor, em detrimento da afinidade com as disciplinas e área do conhecimento.

Quando o aluno se defronta com uma carreira - neste caso, o magistério - pouco valorizada na sociedade, é possível que haja dificuldades de adaptação, como também frustração em relação ao curso escolhido (VIOLIN, 2012). Não obstante, cabe ressaltar que a escolha por um curso de licenciatura não implica necessariamente opção pelo magistério, podendo ser também uma maneira de dar continuidade à vida acadêmica (GOMES, 1998).

Embora as razões que influenciam na opção por determinada carreira sejam diversas, a incongruência entre as expectativas do aluno e a realidade do curso constitui-se como importante fator que contribui para a desistência dos estudantes.

Neste estudo, os sujeitos apontam como uma das principais causas da evasão de acadêmicos o fato de a Licenciatura em Matemática a Distância não ser o curso desejado pelos alunos:

Eu ouvi pessoas que disseram assim: 'olha, eu estou fazendo esse curso porque é o que foi disponibilizado aqui na cidade'. Então, a gente via que haviam motivos diversificados para eles fazerem o curso, e ai começavam a perceber que não é exatamente aquilo que eles imaginavam e acabavam desistindo (Nelize, Professora).

[...] Ter me dado conta de que eu não queria dar aula, e a licenciatura me levaria a ser professor. Então não era o que eu queria (Joaquim, Aluno).

Salienta-se que o fenômeno descrito é comum em outros estudos sobre a mesma temática. Gomes (2011) postula que a falta de interesse pela licenciatura, assim como a decepção com a universidade são razões consideráveis para o abandono do curso superior. Para 33\% dos coordenadores que participaram de uma pesquisa, a desistência ocorreu em virtude da mudança de interesse pessoal ou profissional (NAPOLEÃO FILHO, 2013).

Isso reforça a necessidade de práticas preventivas, que forneçam informações aos estudantes antes da matrícula, de modo que seja possível minimizar o desencontro entre as expectativas e a realidade do curso, assim como um estudo das demandas regionais prévia à oferta.

\section{Dificuldade de conciliar atividades relativas à família e ao trabalho com o curso}

Quando tratamos das causas que influenciam o processo de evasão escolar, a falta de tempo para conciliar atividades profissionais e pessoais com as do curso aparece como um 
dos fatores mais relevantes. Neves (2006), Pacheco (2007) e Biazus (2004) apontam esse aspecto como o que mais atinge alunos que estudam na modalidade a distância no Brasil.

Nessa direção, 56\% dos evadidos que compuseram a amostra de um estudo de Bittencourt e Mercado (2014) responderam que disponibilizavam até cinco horas semanais para as atividades do curso. Os autores observaram, por meio dos dados qualitativos, que esses alunos dedicavam muito tempo ao trabalho e, assim, chegavam em casa cansados e com pouca energia para dedicar-se às tarefas da graduação.

Resultados de outra investigação (ALMEIDA, 2007) também salientam a sobrecarga no trabalho, bem como a falta de tempo para dedicar-se ao curso e a dificuldade em conciliar estudo, trabalho e família como fatores propulsores da evasão.

Concordante com o exposto, os resultados desta pesquisa sugerem significativa dificuldade no que diz respeito ao fato de conciliar as práticas do curso com atividades profissionais e/ou familiares.

Principalmente o tempo, porque na época que eu fiz tinha muito trabalho e eu não conseguia desenvolver, devido ao fato de que eu já era casada, tinha filha, outros afazeres, e não conseguia acompanhar um grupo (Micaela, Aluna).

[...] um curso a distância demanda tempo e, às vezes, o aluno não tem esse tempo disponível ou tem outras prioridades na vida. Também, verificar que não é possível fazer aquele curso por questões familiares ou questões de trabalho (Cristina, Professora).

Observou-se que a falta de tempo decorre de fatores como a alta carga horária dedicada às atividades laborais e às obrigações familiares. "Por causa do trabalho, filho pequeno, e foi muito corrido, não consegui conciliar com a escola. Eu fiz até o quarto semestre. Ai começava o estágio, e eu não ia conseguir conciliar, ai parei (Verônica, Aluna)'”. Sendo assim, a situação de vida dos estudantes, trabalhadores com responsabilidades familiares, também é fator relevante a se considerar quando se analisa a evasão na EaD

\section{Dificuldades acadêmicas}

Ao investigar a percepção de discentes acerca das causas da evasão escolar na Universidade Tecnológica Federal do Paraná (UTFP), Violin (2012) observou que, em geral, a desistência relaciona-se com dificuldades acadêmicas decorrentes do curso. Nesse cenário, os resultados da pesquisa mostraram que $10 \%$ dos alunos evadiram por reprovarem em todas as disciplinas do $1^{\circ}$ semestre. 
Por sua vez, Napoleão Filho (2013) entrevistou coordenadores do Curso de Ciências Econômicas a Distância da Universidade Federal de Santa Catarina (UFSC). Os dados desse estudo mostram que, para 33,81\% dos coordenadores, a dificuldade com provas e exercícios é o principal motivo que acarreta desistência dos alunos. Ainda, para 31\% dos coordenadores, a falta de compreensão das matérias é outra importante causa da evasão escolar.

Nessa direção, Souza (2009) destaca a complexidade das tarefas propostas no curso, assim como a dificuldade do aluno em desenvolvê-las, como fatores que impactam na decisão do aluno de desistir.

De acordo com Violin, o desempenho acadêmico dos evadidos deve ser considerado, pois,

Embora não se possa definir se isso é causa ou efeito do processo de evasão, é possível observar que em geral a desistência está relacionada com uma dificuldade que decorre do curso ou nele se reflete. Isso fica evidente particularmente quando se atenta para as disciplinas com maior número de retenção. (VIOLIN, 2012, p. 85).

Neste estudo, os participantes também apontaram dificuldades acadêmicas como causa fundamental da evasão no CLMD:

Eu acho que é a dificuldade na matéria. A matemática já é difícil, e algumas pessoas têm muita dificuldade, então eles têm aquele monte de matéria, um monte de cálculo. Quando eu estudava no presencial, eu já achava difícil fazer cálculo de limites, derivados, imagina a distância. Então, alguns se desmotivam por causa disso, não conseguem fazer, não entendem. (Caren, Tutora).

Essa manifestação revela como os alunos destacaram a distância entre os conteúdos aprendidos no ensino médio e os temas abordados na graduação e, por conseguinte, a complexidade das atividades propostas no CLMD: “O principal era a distância entre o que eu tinha aprendido no ensino médio e o que era apresentado lá (Lúcia, Aluna)”, “E por causa desse bicho de sete cabeças que eu criei na matemática, porque eu entrei e comecei a ver coisas que eu nunca tinha visto na minha vida (Micaela, Aluna)"'.

Percebe-se, dessa forma, que na visão dos alunos, a complexidade de conteúdos e exercícios, bem como a falta de entendimento sobre deles, provoca desmotivação para prosseguir no curso. Em vista disso, Gomes (2011) postula que muitos alunos, ao reprovarem nas disciplinas, sentem-se desestimulados e acabam desistindo.

\section{Falta de suporte e demora no esclarecimento de dúvidas}

Umekawa (2014) aponta a eficiência das respostas fornecidas pelo tutor às dúvidas dos alunos e a qualidade das interações de aprendizagem que o aluno desenvolve ao longo da sua 
formação, como elementos determinantes para a permanência no curso. Para esse autor, o suporte tecnológico e de tutoria é o principal fator associado à evasão ou à continuidade do discente matriculado na $\mathrm{EaD}$.

Nessa direção, Souza (2009) alude a insatisfação do aluno com tutores e professores como fator que influencia negativamente na decisão de evadir. Por outro lado, sabe-se que um dos principais aspectos responsáveis pelo baixo índice de evasão dos cursos a distância da Fundação Getúlio Vargas (FGV) é a qualidade da interação entre professores e alunos promovida pela tutoria (SOUZA, 2009).

Concordante com o exposto acima, o MEC, por meio da proposição de Referenciais de Qualidade para a EaD (2007), aponta a interatividade entre docentes, tutores e alunos como um dos pilares para garantia da qualidade dos cursos a distância, sendo o tutor fundamental para que o processo de interação, diálogo e feedback ocorra.

A partir das diretrizes do MEC e do referencial fornecido por Umekawa (2014) e Souza (2009), percebe-se a relevância do apoio assistencial aos alunos, seja para o esclarecimento de dúvidas, seja para a promoção da interatividade entre aluno, professores, tutores, e colegas.

Contudo, um dos tutores pesquisados relatou, no trecho destacado abaixo, que os alunos criticavam o pouco contato com os professores e a demora nos feedbacks. Afirmou também que essa condição afetava o rendimento, uma vez que o distanciamento em relação aos professores e a demora no esclarecimento das dúvidas eram fatores complicadores para a realização das atividades dentro dos prazos estabelecidos: “[...] eles reclamaram que às vezes ficavam muito tempo sem resposta, que no fórum eles se sentiam abandonados, que o professor não ia visitá-los (Caren, Tutora)"'.

Por sua vez, os discentes destacaram que os contatos estabelecidos com tutores eram insuficientes, de modo que recebiam, mas com atraso, os feedbacks, seja dos exercícios, seja das avaliações.

Observou-se que essa falta de suporte acarreta, para os alunos, sentimentos de abandono e desmotivação, os quais, por sua vez, podem contribuir consideravelmente para a evasão. "Um pouco abandonado no $\mathrm{EaD}$, como aluno me senti um pouco abandonado (Joaquim, Aluno)',

Eu me decepcionei um pouco com algumas coisas, como a falta de auxílio. Às vezes tinha um trabalho e a gente não conseguia fazer, aí demorava a resposta dos tutores. Sentia falta de esclarecer mais as dúvidas, porque no computador a gente mandava a mensagem e tinha que esperar (Verônica, Aluna). 
Sendo assim, percebe-se que os alunos participantes desta pesquisa possuíam expectativas que não foram supridas no decorrer do curso, destacando-se a falta de suporte e a demora no esclarecimento de dúvidas. Ademais, considerando que a interação do aluno com professores e tutores é concebida como fator indispensável para qualidade dos cursos $\mathrm{EaD}$, o CLMD da UFPel, ao apresentar lacunas, como o distanciamento entre alunos e IES, contribui para a evasão dos seus estudantes, que atingiu a marca de 67,81\% em 2011 (ABED, 2013).

\section{Noção de que o ensino EAD não requer dedicação}

Outro ponto destacado é a percepção prévia ao ingresso no curso que os alunos têm, de que a EaD possui baixa exigência acadêmica. Nessa perspectiva, Souza (2009) alude à "dificuldade de assimilação da cultura EAD" - que diz respeito ao não conhecimento do processo de aprendizagem e da metodologia empregada no curso; há "falha na elaboração do curso" - ou seja, a maneira como o curso está estruturado pode não atender às necessidades de determinado grupo de alunos; assim como "expectativas erradas por parte dos alunos" isto é, quando os estudantes possuem imagem distorcida do curso oferecido.

Esses são aspectos significativos no processo de evasão dos alunos matriculados nessa modalidade: “Eles dizem: 'eu esperava que não precisasse estudar tanto no EaD, e aí descobrem que tem que estudar muito' (Carolina, Coordenadora)",

Muitos evadem por achar que iriam ganhar um diploma simples e, percebem que, na educação a distância, eles precisam estudar, e muito, porque eles são forçados a ter uma autonomia maior de estudo (Thalita, Coordenadora).

Desse modo, percebe-se que as exigências de um curso EaD, tais como bons hábitos de estudo e disponibilidade de horários, frustram parcela dos alunos, haja vista que ingressam na Educação a Distância vislumbrando a possibilidade de adquirir um diploma de curso superior sem despender maiores esforços para o alcance dessa finalidade.

\section{Percepção de ensino com baixa qualidade}

Segundo Souza (2009), o crescimento da Educação a Distância, no decorrer da década de 2000 superou as expectativas, ocasionando significativo grau de preocupação no que concerne à qualidade dos cursos ofertados. De acordo com o Diretor de Regulação e Supervisão em EaD da SEED, é de suma importância apresentar rigor no credenciamento dos 
cursos, bem como acompanhar constantemente as IES que oferecem vagas para que a qualidade dos cursos seja assegurada (SOUZA, 2009).

Nessa direção, a SEED criou referenciais de qualidade para a Educação a Distância a fim de nortear os projetos pedagógicos de cursos EaD. Entre os principais pontos abordados no documento, destacam-se os seguintes tópicos: organização institucional para EaD, que engloba condições para implementação do planejamento de programas, projetos e cursos na modalidade a distância, condições de cumprimento do Plano de Gestão em caráter administrativo e acadêmico, existência de uma unidade específica, responsável pela gestão acadêmica operacional da modalidade $\mathrm{EaD}$, comprovação da existência de processo adequado e periódico de avaliação institucional; corpo social, que se refere à existência de programas para formação e capacitação permanente dos docentes, tutores, corpo técnico e administrativo, políticas de incentivo à produção acadêmica; instalações físicas, que tece a respeito das instalações administrativas envolvidas nas atividades, as quais devem atender requisitos de dimensão, limpeza, iluminação, acústica, ventilação, segurança, conservação e comodidade necessários à proposta, além da comprovação da existência de recursos audiovisuais, incluindo multimídia.

Todavia, Pino (2012) acredita que as diretrizes MEC não são suficientes para assegurar a qualificação de um curso, sendo necessários estudos aprofundados sobre quais seriam os modelos pedagógicos mais adequados à $\mathrm{EaD}$.

Consonante com o exposto, os resultados desta pesquisa indicam que, embora alguns referenciais de qualidade estejam sendo cumpridos pelo CLMD da UFPel, isso não garante a qualidade da oferta, uma vez que os alunos tem uma percepção de baixa qualidade da educação ofertada: “Eu achei ele muito aquém de um curso de graduação, muito fraco, bastante complicado de se fazer, era um atropelo muito grande de conteúdo (Joaquim, Aluno)",

Tinha medo, quando chegou na época de entrar para fazer o estágio, porque eu não me sentia preparada, eu achava o ensino muito fraco para mim entrar em uma sala de aula e ensinar os outros. Na questão do material mesmo, eu acho que era muito fraco para a gente entrar em uma sala de aula. Eu acho que fica meio vago, em algumas coisas, não se consegue aprender (Verônica, Aluna).

Entre os possíveis fatores que motivam essa situação, destaca-se a falta de clareza em relação à metodologia de ensino empregada como a questão da interatividade, tendo em vista que, por meio da análise dos dados, percebe-se que os aspectos metodológicos parecem limitar-se à utilização de recursos tecnológicos, colaborando para uma percepção de relativa 
precariedade do ensino ministrado: "Eu acho que na questão da metodologia, tem os fóruns, os chats, a questão deles participarem das vídeos conferências, enfim (Luciana, Professora)'”,

Nós fizemos um curso pensando na educação a distância, então a gente sempre pensou em utilizar todos os mecanismos e recursos que fossem possíveis para que o aluno aprendesse matemática a partir das tecnologias de informação e comunicação. Então, nos utilizamos de Web Conferências, Chats, fóruns, blogs (Pamela, Professora).

Verificou-se pelo discurso dos alunos evadidos, que a percepção de um ensino pouco qualificado contribuiu significativamente para a evasão, considerando que relataram não se sentirem preparados para o exercício da profissão, assim como o fato de não alcançarem domínio teórico dos conteúdos ministrados. Portanto, pode se indagar até que ponto a expansão do acesso à educação superior, por meio da EaD, tem alcançado seus objetivos, considerando as altas taxas de evasão e, pelo menos, a percepção de que não oferece ensino de qualidade, dentro das expectativas dos estudantes.

\section{Ausência de práticas preventivas à evasão}

Percebeu-se, ainda, que não existem, no CLMD, mecanismos sistemáticos para o controle da evasão. Conforme manifestado nos relatos abaixo, as práticas de combate à evasão limitam-se ao contato entre tutor e aluno, na busca de identificar o motivo que levou à desistência. Não obstante, não foram citadas, pelos coordenadores, práticas preventivas.

Quando um aluno começa a não frequentar ou não enviar as suas atividades, a nossa equipe dentro do polo se comunica com esse aluno através das diversas mídias (Renata, Coordenadora).

Antes de desligar qualquer aluno, a gente procura sempre fazer contato com os tutores presenciais, que são os sujeitos que estão mais próximos dos alunos. Então esse tutor é o nosso caminho, é o nosso mediador entre a coordenação do curso e o aluno (Thalita, Coordenadora).

Em seu estudo, Santos et al. (2008, p. 9) defendem a necessidade de oferecer ações que promovam "o estar junto virtual", de modo a propiciar o senso de pertencimento ao aluno, além da oferta de um tutor presencial em tempo integral e cursos de nivelamento a fim de minimizar o distanciamento entre as demandas do curso superior e o conhecimento prévio do aluno.

Além disso, tendo em vista a incongruência entre as expectativas de parte dos pesquisados com o que é oferecido no CLMD, salienta-se a necessidade de prestar 
esclarecimentos aos estudantes, principalmente no que se refere ao significado do ensino a distância, suas características, procedimentos metodológicos e objetivos.

Também deve-se mostrar a importância de desenvolver habilidades no uso das TIC e ter acesso aos recursos do computador e da internet, evitando, assim, que o aluno tenha contato com algo desconhecido, como, em determinados casos, o uso da internet.

Destaca-se, ainda, a necessidade de tornar o curso mais atraente, por meio da promoção de grupos de estudo, oficinas, seminários, projetos, pesquisa e atividades de extensão que envolvam os alunos, de forma a torná-los mais engajados nas atividades relativas ao curso.

Reflete-se, portanto, que a ausência de tais medidas colaboram sensivelmente para a manutenção do desencontro entre as expectativas dos alunos e a realidade do ensino EaD e, por conseguinte, com o processo de evasão.

\section{Considerações finais}

Após sistematização e análise dos dados obtidos, foi possível verificar que, na visão de coordenadores, professores, tutores e alunos, a evasão ocorreu por diferentes fatores, todos relacionados, de alguma forma, ao curso escolhido, ao Ensino a Distância ou às próprias características dos alunos evadidos.

Na visão dos pesquisados, uma das principais causas da evasão dos acadêmicos é o fato de a Licenciatura em Matemática a Distância não ser o curso desejado por parte dos alunos. Os alunos evadem pela não correspondência do curso às expectativas iniciais, o que provoca desmotivação e favorece a evasão. Outro ponto destacado é a percepção que os alunos têm de que a EaD tem baixa exigência acadêmica, o que não se verifica, pois o curso demanda hábitos de estudo e disponibilidade de horários.

O distanciamento entre estudantes e instituição em que estão matriculados é um fator que motiva a evasão. Os alunos sentem-se abandonados e não buscam o contato presencial com o polo. Além disso, o corpo docente destacou que, muitas vezes, a Licenciatura em Matemática não é o curso desejado pelos alunos, fato que favorece o abandono.

Já os tutores apontaram as dificuldades acadêmicas como causa fundamental da evasão no CLMD. Para eles, a natureza do curso, com conteúdos e exercícios próprios da formação matemática, nem sempre são de fácil entendimento.

Por sua vez, discentes destacam a falta de tempo para conciliar atividades profissionais e pessoais, sendo esse um dos fatores mais relevantes para os alunos. Os estudantes também 
destacaram as dificuldades acadêmicas como determinantes para o abandono, citando a distância entre os conteúdos estudados no ensino médio e os temas abordados no curso.

Também mencionaram o fato de a Licenciatura em Matemática a Distância não ser o curso desejado, uma vez que não planejavam lecionar após a conclusão da graduação, indo, assim, ao encontro da visão dos coordenadores. Focalizando aspectos relacionados ao curso, percebeu-se a demora nos feedbacks e o descontentamento dos alunos com a qualidade da oferta.

Como se pode verificar, a evasão é um fenômeno multifacetado, ligado a uma multiplicidade de fatores, o que torna sua superação complexa e desafiadora. Sem a pretensão de encerrar a discussão da evasão na $\mathrm{EaD}$, este estudo aponta para a necessidade de realização de outros estudos que incluam alunos evadidos de outros cursos nessa modalidade, buscando desvelar dificuldades e pretensões e, quem sabe, abrangendo as demais licenciaturas da UFPel/UAB, dado os relevantes índices de evasão que alcançam.

\section{Referências}

Associação Brasileira de Educação a Distância. Censo EAD.BR: relatoria analítico da aprendizagem a distância no Brasil. Disponível em:

<http://www.abed.org.br/censoead2013/CENSO_EAD_2013_PORTUGUES.pdf>. Acesso em: 25 abr. 2016.

ALMEIDA, Onília Cristina de Souza de. Evasão em cursos a distância: validação de instrumento, fatores influenciadores e cronologia da desistência. 2007. $164 \mathrm{f}$.

Dissertação (Mestrado em Gestão Social e Trabalho) - Universidade de Brasília, Brasília, 2007.

ALMEIDA, Onilia Cristina de Souza de. Gestão das Organizações Complexas: O Caso do Sistema Universidade Aberta do Brasil na Universidade de Brasília. 2013. 253 f. Tese (Doutorado em Educação) - Faculdade de Educação. Programa de Pós-Graduação em Educação, Universidade de Brasília, Brasília-DF, 2013.

BIAZUS, C. A. Sistema de fatores que influenciam o aluno a evadir-se dos cursos de graduação na UFSM e na UFSC: um estudo no curso de Ciências Contábeis. 2004152 f. Tese (Doutorado) - Programa em Engenharia de Produção, Universidade Federal de Santa Catarina, 2004.

BITTENCOURT, Ibsen Mateus; MERCADO, Luis Paulo Leopoldo. Evasão nos cursos na modalidade de educação a distância: estudo de caso do Curso Piloto de Administração da UFAL/UAB. Ensaio: Avaliação e Políticas Públicas em Educação, [s.1.], v. 22, n. 83, p. 465-504, 2014. 
BRASIL. Decreto-lei n o 9.394, de 20 de dezembro de 1996. Estabelece as Diretrizes e Bases da Educação Nacional. Disponível em:

<http://www.planalto.gov.br/ccivil_03/LEIS/L9394.htm>. Acesso em: 14 de jun. 2013.

BRASIL. Decreto-lei no 2.494, de 10 de fevereiro de 1998. Regulamenta o art. 80 da Lei n 9.394, de 20 de dezembro de 1996, e dá outras providências. Disponível em: <http://www.planalto.gov.br/ccivil_03/decreto/D2494.htm>. Acesso em: 13 de jun. 2013

BRASIL. Decreto-lei n o 13.005/2014, de 25 de junho de 2014. Legislação Federal do Brasil. Diário Oficial da União. 26 de junho de 2014. p.1. Disponível em: $<$ http://pesquisa.in.gov.br/imprensa/jsp/visualiza/index.jsp?data=26/06/2014\&jornal= 1000\&pagina=1\&totalArquivos=8>. Acesso em: 27 jun. 2014.

CASTRO, Alda Maria Duarte Araújo. Educação a distância e formação de professores: limites e possibilidades. In: Neto, Antônio Cabral (Org.): Política educacional: desafio e tendências. Porto Alegre: Sulina, 2004 p. 97-124.

COELHO, Maria de Lourdes. A Evasão nos Cursos de Formação Continuada de Professores Universitários na Modalidade de Educação a Distância Via Internet. Universidade Federal de Minas Gerais, 2002. Disponível em:

<http://www.abed.org.br/site/pt/midiateca/textos_ead/626/2004/12/a_evasao_nos_cu>. Acesso em 30 mar. 2014.

FAVERO, Rute Vera Maria. Dialogar ou evadir: Eis a questão! Um estudo sobre a permanência e a evasão na Educação a Distância. 2006, 167 f. Dissertação (Mestrado em Educação) - Faculdade de Educação, Universidade Federal do Rio Grande do Sul, Porto Alegre, 2006.

GOMES, Alberto Albuquerque. Evasão e evadidos: o discurso dos ex-alunos sobre evasão escolar nos cursos de licenciatura. 1998. 161 f. Tese (Doutorado em Educação) Universidade Estadual Paulista, Marilia, 1998.

GOMES, Fernando Costa Fernandes. A desistência de alunos na licenciatura em Física no Instituto Federal de Educação, Ciência e Tecnologia do Rio Grande do Norte (IFRN): causas e sugestões para o combate. 2011, 617 f. Dissertação - Programa de PósGraduação em Ensino de Ciências Naturais e Matemática da Universidade Federal do Rio Grande do Norte, Natal, 2011.

JOHANN, Cristiane Cabral. Evasão escolar no Instituto Federal SulRio-Grandense: Um estudo de caso no Campus Passo Fundo. 2012, 118 f. Dissertação (Mestrado em Educação) - Programa de Pós-Graduação em Educação, Universidade de Passo Fundo, Passo Fundo, 2012. 
LONGO, Carlos Roberto Juliano. Educação a Distância. In: LITTO, Frederic Michael; FORMIGA, Manuel Marcos Maciel (Org.) Educação a Distância. O estado da arte. São Paulo: Pearson Education do Brasil, 2009. p. 219-222.

MEC. MINISTÉRIO DA EDUCAÇÃO. Plano Nacional de Educação-PNE Projeto de Lei aprova o Plano Nacional de Educação para o decênio 2011-2020. Disponível em: <http://portal.mec.gov.br/index.php?option=com_content\&id=16478\&Itemid=1107>, 2013. Acesso em: 01 mar. 2014.

MEC - MINISTÉRIO DA EDUCAÇÃO. Diplomação, retenção e evasão nos cursos de graduação em instituições de ensino superior públicas. Comissão especial de estudos sobre a evasão nas universidades públicas brasileiras, 1997. Disponível em:

<http://www.andifes.org.br/wp content/files_flutter/Diplomacao_Retencao_Evasao_Graduacao_em_IES_Publicas1996.pdf> Acesso em: 10 mar. 2014.

MILL, Daniel. A Universidade Aberta do Brasil. In: LITTO, Frederic Michael; FORMIGA, Manuel Marcos Maciel (Org.) Educação a Distância: o estado da arte. v. 2, 2. ed. São Paulo: Pearson Education do Brasil, 2012, p. 280-291.

MINAYO, M. C. de S. Pesquisa social: teoria, método e criatividade. 2 ed.

Petrópolis, RJ: Vozes, 2010.

MORAES, Roque; GALIAZZI, Maria do Carmo. Análise textual discursiva. Ijuí: Unijuí, 2007.

NAPOLEÃO FILHO, Jair. Causas para a evasão dos alunos de graduação a distância em Ciências Econômicas da Universidade Federal de Santa Catarina.

2013. 193 f. Dissertação (Mestrado em Administração) - Programa de PósGraduação em Administração, Universidade Federal de Santa Catarina, Florianopólis, 2013.

NEVES, Yára Pereira da Costa e Silva. Evasão nos cursos a distância curso de extensão TV na Escola e os Desafios de Hoje. 2006, 96 f. Dissertação (Mestrado em Educação Brasileira) - Programa de Pós-Graduação em Educação Brasileira, Universidade Federal de Alagoas, Alagoas, 2006.

PACHECO, Andressa Sasaki Vasques. Evasão: análise da realidade do curso de graduação em Administração a Distância da Universidade Federal de Santa Catarina. 2007, 136 f. Dissertação (Mestrado em Administração) - Programa de Pós-Graduação em Administração, Universidade Federal de Santa Catarina, Florianópolis, Santa Catarina, 2007. 
PINO, Adriana Soeiro. Curso de Pedagogia online: os referenciais de qualidade da EAD. 2012. 112 f. Dissertação (Mestrado em Educação) - Programa de Pós-Graduação em Educação -, Universidade Nove de Julho, São Paulo, 2012.

SANTOS, Elaine Maria dos et al. Evasão na educação a distância: identificando causas e propondo estratégias de prevenção. In: $1^{\circ}$ CONGRESSO INTERNACIONAL ABED DE EDUCAÇÃO A DISTÂNCIA. Santos: Abed, 2008. p. 1 - 10. Disponível em: <http://www.abed.org.br/congresso2008/tc/511200845607PM.pdf>. Acesso em: 31 ago. 2016.

SEIDMAN, Irving. Interviewing as qualitative research: a guide for researches in education and the social sciences. New York: Teachers College Press; 1998.

SILVA FILHO, Roberto Leal Lobo E et al. A evasão no ensino superior brasileiro. Cadernos de Pesquisa, v. 37, n. 132, 2007, Instituto Lobo para o Desenvolvimento da cia e da Tecnologia. Disponível em: . Acesso em: 5 abr. 2014.

SILVEIRA, Cláudia Alexandra Bolela. Educaçao a distância e a evasão: estudo de caso da realidade no Polo UAB de Franca. Curso de Especialização em Educação Continuada e a Distância da UnB. Simpósio Internacional de Educação a Distância, Encontro de Pesquisadores em Educação a Distância, Universidade Federal de São Carlos, UFSCar, 2012.

SOUZA, Conceição Aparecida Nascimento de. Um estudo sobre as principais causas da evasão na educação a distância. 2009. 66 f. Dissertação (Mestrado em Administração Pública) - Fundação Getúlio Vargas, São Paulo, 2009.

SOUZA, Paulo Nathanael Pereira de. LDB e ensino superior: estrutura e funcionamento. São Paulo: Pioneira, 1997.

UMEKAWA, Elienay Eiko Rodrigues. Preditores de fatores relacionados à evasão e à persistência discente em ações educacionais a distância. 2014. 256 f. Dissertação (Mestrado em Ciências) - Programa de Pós-graduação em Psicologia -, Universidade de São Paulo, Ribeirão Preto, 2014.

VIOLIN, Lilian Aparecida Berwanger. Evasão Escolar na Educação Superior: Percepções de Discentes. 2012. 94 f. Dissertação (Mestrado em Tecnologia) - Programa de Pós Graduação em Tecnologia, Universidade Tecnológica Federal do Paraná, Curitiba, 2012. 
Mestre em Política Social E-mail: marleyradin@gmail.com

Stivie Sena Leston

Universidade Católica de Pelotas - Brasil

Graduando de Psicologia e bolsista de Iniciação Científica PIBIC/CNPq Grupo de Pesquisa: Grupo interdisciplinar de estudos e pesquisas em Política de Educação

E-mail: stivie.sena@hotmail.com

Dr $^{a}$ Myriam Siqueira da Cunha Universidade Católica de Pelotas - Brasil Programa de Pós-Graduação em Política Social da Universidade Católica de Pelotas

(PPGPS/UCPEL).

Grupo de Pesquisa: Grupo interdisciplinar de estudos e pesquisas em Política de Educação

E-mail: mscpel@gmail.com

Recebido em: 06 de junho de 2016.

Aprovado em: 21 de agosto de 2016 